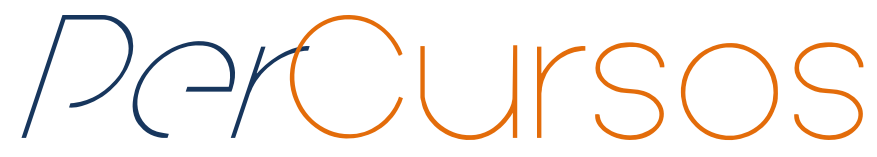

\title{
Narrativas sobre gênero e diversidade sexual no ensino e na formação de professoras e professores
}

\section{Resumo}

Este trabalho tem como objetivo analisar as narrativas de professoras e professores, localizando suas concepções docentes sobre gênero e diversidade sexual através da investigação de aspectos de suas experiências de vida que colaboraram de modo significativo para essas concepções. Interessa-nos também saber sobre as repercussões dessas concepções no contexto escolar, assim como analisar como o currículo contribuiu/contribui para o estudo de gênero e sexualidade no ensino e na formação de professoras e professores. A pesquisa foi realizada com docentes da rede municipal e estadual da cidade do Recife. Para coleta de dados, utilizamos a entrevista narrativa. De acordo com as entrevistas que realizamos, percebemos que devido às violências sofridas e/ou praticadas por algumas (uns) das (os) docentes, suas concepções, hoje, são de que gênero são construções socioculturais e que sexualidade vai muito além de questões biologizantes. Mas cabe salientar aqui que essas novas concepções só foram entendidas por essas/esses docentes pelas violências sofridas/praticadas e pela busca de maiores informações sobre o tema, pelas redes de amigas e amigos LGBT e pela inserção nos movimentos sociais, tanto nos movimentos feministas, como também nos movimentos LGBT. As (os) docentes afirmaram também que o currículo educacional em nada contribuiu para suas formações.

Palavras-chave: Gênero; Diversidade sexual; Formação docente.

\author{
Suelem Duarte Barros \\ Graduanda em Pedagogia na \\ Universidade Federal de \\ Pernambuco - Brasil
}

duartepedagoga@gmail.com

\section{Jaileila de Araújo Menezes \\ Doutora em Psicologia pela Universidade Federal do Rio de Janeiro. Professora da \\ Universidade Federal de Pernambuco - Brasil jaileila@terra.com.br}

\begin{abstract}
Para citar este artigo:
BARROS, Suelem Duarte; MENEZES, Jaileila de Araújo. Narrativas sobre gênero e diversidade sexual no ensino e na formação de professoras e professores. Revista PerCursos. Florianópolis, v. 15, n. 29, p. 169 201, jul./dez. 2014.
\end{abstract}

DOI: $10.5965 / 1984724615292014169$

http://dx.doi.org/10.5965/1984724615292014169 


\title{
Narratives about gender and sexual diversity in education a nd training of teachers
}

\begin{abstract}
This work aims to analyze the narratives of teachers, in order to find out their teaching conceptions about gender and sexual diversity through a research into aspects of their life experiences that contributed significantly to these conceptions. It Interests us also to know about the impact of these concepts in the contexts of the schools, as well as to analyze how the syllabus contributed/contributes to the study of gender and sexuality in education and teacher training. The research was conducted with teachers from municipal and state teacher of the city of Recife. For data collection, we have used a narrative interview. According to the interviews we made, we realized that due to the violence suffered and/or practiced by some of the teachers, their conceptions today are that gender consists of sociocultural constructions and that sexuality goes far beyond biologizing issues. But it should be noted here that these new concepts were only understood by these teachers by the violence suffered/practiced and by the search for more information on the subject, by the networks of LGBT friends and by the insertion in social movements, both in feminist and LGBT movements. The teachers also stated that the educational syllabus in no way contributed to their formation.
\end{abstract}

Keywords: Gender;

Sexual diversity; Teacher training. 


\section{Introdução}

As variadas formas de expressões da sexualidade humana ainda são um problema presente e constante na sociedade ocidental, principalmente se tratando das identidades de gênero e orientação sexual LGBT (lésbicas, gays, bissexuais, travestis e transexuais). Ao longo de sua existência, as instituições educacionais (formais e não formais), com os seus currículos ocultos ou não, atribuem valores, normas e crenças para inferiorizar/oprimir/silenciar as identidades LGBT, rotulando-as de estranhas, pecadoras, pervertidas, promíscuas, criminosas, portadoras de alguma doença contagiosa; sempre valorizando a heteronormatividade e o sexismo existente na nossa sociedade, centrados no papel do homem, adulto, branco, heterossexual, burguês, física e mentalmente "normal". Entendemos que a educação é um importante instrumento para enfrentar situações de preconceito e discriminação, porém o que observamos, mesmo com as transformações que estão acontecendo na sociedade ${ }^{1}$ e no campo educacional brasileiro - com a implementação dos Parâmetros Curriculares Nacionais (PCN) -, é que os currículos das instituições educacionais, em vez de trabalharem questões relativas aos Direitos Sexuais, reproduzem lógicas perversas de opressão contra as identidades LGBT, o que acarreta professoras (es) ${ }^{2}$, pedagogas (os) despreparadas (os) para atuarem nas instituições educacionais em respeito às prerrogativas dos Direitos Humanos e Direitos Sexuais. Em sua formação, essas (es) sujeitas (os) aprendem a negar ou silenciar seus desejos e na sua docência continuam reproduzindo práticas de uma cultura heteronormativa e sexista, formando assim um ciclo vicioso de ensino-aprendizado pautada em práticas discriminatórias e de exclusão.

Durante a nossa formação, passando pela educação infantil, ensino fundamental e ensino médio e até mesmo na nossa formação acadêmica universitária, nossas

\footnotetext{
${ }^{1}$ As mudanças ocorridas nas últimas décadas são: cirurgia de mudança de sexo pelo Sistema Único de Saúde, direitos aos casais homoafetivos de adotarem crianças, direito às (aos) travestis e transexuais de usarem nome social, direito de incluir a companheira ou o companheiro como dependente na declaração do Imposto de Renda, direito a receber pensão pela morte de seu cônjuge, reconhecimento da união estável, licença-maternidade para mãe ou pai adotivo e o mais recente, o casamento civil para as (os) LGBT.

${ }^{2}$ Neste trabalho vamos utilizar sempre as palavras no feminino, para dar visibilidade a este gênero, uma vez que trata-se de um trabalho focado nas relações de gênero e diversidade sexual.
} 
orientações sexuais e identidades de gênero são silenciadas/negadas, por não entendermos as subjetividades e culturas que são transmitidas nos livros didáticos, nas posturas das (os) professoras (es), nos maneirismos dados a cada gênero, até que no ensino médio nossas posturas já estão moldadas conforme o modelo da sociedade dominante. Aprendemos a calar e recusar nossos jeitos e desejos, introjetando que nós é que somos estranhas (os)/anormais. Nenhum trabalho sobre educação sexual esclarece àas alunas e aos alunos sobre a diversidade de expressões das sexualidades humanas, uma vez que seu estudo é relegado apenas às questões relativas à virgindade, gravidez na adolescência e doenças sexualmente transmissíveis DSTs/Aids.

No campo acadêmico, no curso de Pedagogia da Universidade Federal de Pernambuco/UFPE, sabemos que os estudos de gênero e sexualidade ainda são muito escassos, trabalhados apenas por pessoas/estudantes que se interessam pelo tema. Isso é consequência de um currículo que emudece/denega as diversas formas da sexualidade humana e os estudos sobre gênero, pois nos cursos de licenciatura, por exemplo, não existe a disciplina de sexualidade. Em Pernambuco, apenas no curso de Pedagogia da UFPE essa disciplina é ofertada, porém eletiva, não alcançando todas (os) estudantes do curso. Nas dissertações e teses, geralmente são apresentadas também questões sobre gravidez na adolescência e as DSTs/Aids, muitas delas pesquisas realizadas através de oficinas que são oferecidas por Ongs. Este trabalho, portanto, surgiu da necessidade de ser um instrumento de estudo e reflexão para contribuir com os estudos sobre gênero e diversidade sexual no ensino e formação de professoras e professores.

Portanto, neste trabalho, temos o objetivo de analisar as narrativas de professoras e professores da cidade do Recife, localizando suas concepções docentes sobre gênero e diversidade sexual investigando aspectos de suas experiências de vida que colaboraram de modo significativo para essas concepções. Interessa-nos também saber sobre as repercussões dessas concepções no contexto escolar, assim como analisar como o currículo contribuiu/contribui para o estudo de gênero e sexualidade no ensino e na formação de professoras (es). 


\section{Referencial teórico}

Heteronormatividade e sexismo na sociedade ocidental

Ao longo de sua história, as mulheres e as lésbicas, gays, bissexuais, travestis e transexuais foram silenciadas (os) pela nossa cultura esmagadora das diferenças. Como nos alerta Guacira Lopes Louro (2009), foi a partir do século XIX, com a revolução industrial e a revolução burguesa, que se tentou definir a sexualidade, passando a receber uma atenção especial pelo Estado e pelos indivíduos, ocorrendo uma distribuição diferente de homens e mulheres no mercado de trabalho. Vale ressaltar que, nessa mesma época, as discussões nas sociedades ocidentais eram acerca das diferenças anatômicas entre homens e mulheres; estas eram consideradas como portadoras de imperfeições no seu corpo, portanto, a imagem principal das sociedades estava voltada para o homem (LAQUEUR, 1990 apud. Louro, 2009). A partir do final do século XIX, diversos "especialistas" - homens, brancos, médicos, filósofos - de países desenvolvidos europeus, deram novas definições sobre os corpos dos homens e das mulheres. Assim, “discursos impregnados de autoridade da ciência, tinham estatuto de verdade, combinando com outros, como os da Igreja, da moral, da lei” (LOURO, 2009, p. 88).

Daí, passamos a ser governadas (os) por um paradigma de diferença entre homens e mulheres e lésbicas, gays, bissexuais, travestis, transexuais e heterossexuais. Do nosso nascimento (ou até mesmo antes dele, quando os pais fazem a ultrassonografia para saber o sexo biológico do bebê, tudo já é definido como coisas de menina e coisas de menino), somos acionados a assumir determinada identidade construída de gênero. $O$ menino deve ser aquele garoto durão, que fala alto, que corre, que pode se sujar; enquanto que para a menina são relegados os papéis de educada, meiga, com letrinhas bem bonitinhas, carinhosa, dentre outros.

É nesse contexto que surgem a imagem da mulher submissa e a figura do público LGBT, tratada como pessoa de práticas desviantes das ditas práticas “normais". Basta que uma/um aluna (o) tenha atitudes em sala de aula que não correspondam ao seu gênero, ou melhor, que foram denominados inapropriados para seu gênero, que as (os) 
colegas passam a agredir essa/esse aluna (0) com apelidos de cunho lesbofóbico, homofóbico e transfóbico, tais como: sapatão, "mulher macho”, "veado”, "maricona”, "traveco", "trava”. E, para piorar, as professoras e professores não sabem lidar com isso e reproduzem essas atitudes homofóbicas ou se calam diante de tal situação.

Silenciosas (os), silenciadas (os), essas/esses sujeitas (os) por várias vezes transgrediram para tentar negar sua invisibilidade social. Percebemos isso nos atuais movimentos de defesa dos Direitos Humanos, tanto de mulheres, como LGBT; dessa maneira esses grupos têm tentado subverter toda uma cultura estabelecida há anos, por outras que sejam mais humanas e respeitosas diante das diferenças de outrem. Assim, tais movimentos, nas últimas décadas, têm conseguido inspirar novos conceitos de família, contribuindo para mudanças nos campos jurídico, midiático e educacional.

Porém, mesmo com todos esses avanços, mulheres continuam sendo vitimadas sexualmente e o número de LGBT assassinadas (os) por ano, por conta da lesbofobia, homofobia, bifobia, transfobia cresce a dados assustadores e com requintes de crueldade. Segundo estudos do GGB (Grupo Gay da Bahia - uma ONG voltada para os direitos LGBT), o Brasil é o país com a maior quantidade de registros de crimes lesbofóbicos, homofóbicos, bifóbicos e transfóbicos do mundo. Só em 2012 foram documentados 338 assassinatos de lésbicas, gays, bissexuais, travestis e transexuais. Sabemos que isso é reflexo de um conjunto de fatores, tais como: a não criminalização da homofobia, ausência de punições severas para pessoas que cometeram tal crime; mas também a falta de estudos sobre gênero e diversidade sexual no ensino e na formação de professoras (es), pois como dissemos acima a educação é um importante instrumento para enfrentar situações de preconceito e discriminação.

Travestis e transexuais: educação trans-tornada

Antes de iniciarmos esse subcapítulo, exporemos algumas diferenças entre travestis e transexuais. Não pretendemos conceituá-las, uma vez que isso limitaria muito 
a orientação e a identidade de gênero dessas pessoas. Siqueira (2009), de modo bastante rápido faz uma definição para as duas, assim o autor supracitado afirma:

(...) defino as travestis como pessoas que se identificam com a imagem e o estilo feminino, apropriando-se de indumentárias e adereços de sua estética, realizando com frequência a transformação de seus corpos, quer por meio da ingestão de hormônios, quer através da aplicação de silicone industrial e das cirurgias de correção estética e de próteses. As transexuais são pessoas com demandas de cirurgias de mudança de sexo e de identidade civil, demandas que não encontramos nas reivindicações emancipatórias das travestis. (SIQUEIRA, 2009, p. 236)

Essa definição, para os tempos atuais, limita muito a condição dessas pessoas, uma vez que temos conhecimento acerca de travestis masculinas - aquelas que nascem mulheres, mas se travestem de homens -, assim como também sabemos que uma transexual, tanto masculina como feminina, não sente e nem precisa necessariamente realizar uma cirurgia de mudança de sexo para se afirmar como tal. Não pretendemos aprofundar esse aspecto, mas apenas pontuar algumas diferenças, pois o que nos interessa aqui é apresentar a educação escolar transtornada pela qual essas pessoas passam ou passaram durante suas vidas.

Por conta de todo processo de transformação a que as travestis e transexuais são submetidas, a família, por questões histórico-culturais heteronormativas acaba renegando essas/esses sujeitas (os), que por consequência dessa rejeição são obrigadas (os) a irem em busca de outros lares, onde formam novos arranjos familiares. Como se não bastasse a exclusão dessas pessoas pela família e pela comunidade, a escola também passa a ser um local aterrorizador, uma vez que as pessoas da comunidade escolar acabam reproduzindo as lógicas perversas de opressão e discriminação; ou, muitas vezes, não sabem lidar com a figura dessa travesti e transexual e acabam fingindo que nada está acontecendo, fechando os olhos para as cenas de travestifobia e transfobia dentro da instituição. 
Uma das cenas mais excludentes nas escolas para as travestis e transexuais, além das agressões verbais, quando não as físicas, é a relacionada ao uso do banheiro. As professoras e professores devem saber lidar e respeitar a identidade de gênero de todas e todos, garantindo a utilização do banheiro designado para tal gênero como forma de preservar a dignidade humana dessas cidadãs e cidadãos. Impor-Ihes a utilização de um banheiro não compatível com sua identidade de gênero é uma atitude discriminatória. Separar um banheiro para pessoas LGBT também é uma atitude discriminatória e segregatista, sendo assim incompatível com os direitos humanos.

Devido a toda essa travestifobia e a transfobia existente em nossa sociedade, muitas (os) travestis e transexuais acabam largando a escola ainda muito cedo, e sendo obrigadas (os) a desempenhar trabalhos relacionados à beleza e ao sexo. Marina Reidel ${ }^{3}$, em sua dissertação de mestrado afirma que suas sujeitas de pesquisa (transexuais e travestis) não sofreram nenhum tipo de agressão por parte de alunas (os) e mães/pais na comunidade escolar. O problema foi com as (os) professoras e as direções. Segundo a mesma:

A escola ainda é um espaço homofóbico e transfóbico. Os professores ainda não estão preparados para lidar com essas questões. Eles não foram preparados para isso porque as universidades não trabalham essas questões. (REIDEL, 2013, In: http://www.sul21.com.br/jornal/a-escolaainda-e-um-espaco-homofobico-e-transfobico-diz-marina-reidel/)

Em um estudo focado nas travestis, Luma Nogueira Andrade ${ }^{4}$, em sua tese de doutorado intitulada "Travestis na escola: Assujeitamento ou resistência à ordem normativa", faz um levantamento das travestis matriculadas na rede estadual de ensino do Ceará e narra os maus-tratos sofridos por elas no ambiente escolar. Assim como na

\footnotetext{
3 Primeira transexual feminina a conquistar o título de Mestre pela Faculdade de Educação da UFRGS (Universidade Federal do Rio Grande do Sul), intitulada "A pedagogia do salto alto - Histórias de professoras transexuais e travestis na Educação Brasileira”, a pesquisa estuda a inserção de sete professoras trans em escolas de diferentes regiões do país.

${ }^{4}$ Primeira travesti doutora em educação do Brasil, pela UFC (Universidade Federal do Ceará) e docente da Universidade da Integração Internacional da Lusofonia Afro-Brasileira (Unilab), em Redenção.
} 
pesquisa de Reidel, Luma concluiu que falta aos professores e gestores uma formação que vá além do conteúdo das disciplinas e dê conta das questões de gênero não apenas para tratar da homossexualidade no currículo, mas principalmente lidar com as especificidades de cada pessoa (ANDRADE, 2012).

Algumas pesquisas na área da diversidade sexual apontam que de toda comunidade LGBT, as travestis e as transexuais são as mais prejudicadas no processo escolar pelos seus trejeitos e comportamentos ao avesso do designado pelo seu gênero. Percebemos dessa maneira, o mundo transtornado a que essas/esses sujeitas (os) estão designadas (os) a viver; um mundo marginalizado e cruel, tudo isso porque romperam com os padrões morais e estéticos pré-estabelecidos para nossa sociedade por grupos que se acham superiores a elas (es). A escola, lugar onde deveriam se formar pessoas livres de preconceito e que respeitassem a diversidade do outro, com uma educação voltada para a inclusão, acaba desempenhando funções que não são de sua esfera, tal qual afirma Siqueira: "Torna-se uma escola-polícia, escola-igreja, escola-tribunal, orientada por tecnologias sofisticadas de poder centradas na disciplina dos corpos e na regulação dos prazeres" (SIQUEIRA, 2009, p. 249).

Parâmetros Curriculares Nacionais e orientação sexual nas escolas e na formação de professoras (es)

Publicados em 1997, pela secretaria de educação, os Parâmetros Curriculares Nacionais - Orientação sexual - foram adotados como tema transversal. Isso significa que todas (os) professoras (es), podem trabalhar conteúdos ligados à sexualidade, uma vez que ela está presente no cotidiano escolar, seja nas conversas pelos corredores, nas roupas, nas músicas e danças, assim como também nos livros didáticos trabalhados em sala de aula. Os PCN's surgiram quando o Estado brasileiro percebeu que crescia o número de adolescentes grávidas, assim como o aumento do número de pessoas contaminadas pelo vírus HIV/Aids; desse modo, o tema da sexualidade deixou de ficar mais restrito à esfera familiar e passou a ser indicado como tema a ser trabalhado no núcleo educacional (ALTMANN, 2001). Segundo a mesma autora: 
A fim de atingir os objetivos propostos pelos PCN's, o tema transversal da orientação sexual deve impregnar toda a área educativa do ensino fundamental e ser tratado por diversas áreas do conhecimento. $O$ trabalho de orientação sexual deve, portanto, ocorrer de duas formas: dentro da programação, através de conteúdos transversalizados nas diferentes áreas do currículo, e como extraprogramação, sempre que surgirem questões relacionadas ao tema. Este tema deve ser tratado ao longo de todos os ciclos de escolarização, todavia, "a partir da quinta série, além da transversalização (...), a Orientação Sexual comporta também uma sistematização e um espaço específico". Isso indica uma intensificação dos trabalhos de orientação sexual na escola a partir deste ciclo. Os programas de orientação sexual devem ser organizados em torno de três eixos norteadores: "Corpo: matriz da sexualidade", "Relações de gênero" e "Prevenção de doenças sexualmente transmissíveis/AIDS”. (ALTMANN, 2001, p. 580)

Assim, como o nome já indica, os temas transversais são assim chamados por não pertencerem a nenhuma disciplina específica, podendo qualquer docente fazer uso do mesmo em sala de aula. As (os) docentes também não são obrigadas (os) a trabalharem tais temas, logo ficam na invisibilidade do currículo educacional. Muitas vezes, isso se dá pelo fato das professoras (es) não se sentirem preparadas (os) para lidar com o tema e com situações inesperadas que ocorrerem no dia a dia da sala.

Porém, sabemos que questões de gênero e sexualidade são temas que permeiam as conversas dentro e fora das salas de aula, logo, a Educação Sexual, como propõem os PCN's é de grande importância para a formação de crianças e adolescentes, uma vez que a sexualidade não está restrita à atividade genital, nem à reprodução, vai além de necessidades fisiológicas (FAVA, 2008).

Sabemos que não é com a adoção dos PCN's que a Educação Sexual passará a ser trabalhada, pois há muitas críticas de pesquisadoras e pesquisadores da educação em relação ao uso dos mesmos, uma vez que as (os) docentes precisam passar por uma formação continuada para enfrentar dificuldades do dia a dia e quebrar os tabus e preconceitos estabelecidos historicamente. Como afirma Fava (2008), em sua pesquisa sobre o uso dos PCN's em sala de aula: 
Aprender a trabalhar com Educação Sexual não é algo que acontece rapidamente, com apenas alguns cursos, mas requer um processo contínuo de formação, em que os educadores possam adquirir conhecimentos científicos, rever posturas, questionar valores e preconceitos, trocar experiências, confrontar opiniões, de modo a construir novos saberes e descobrir outras possibilidades de atuação nesta área. (FAVA, 2008, p.154)

Portanto, percebemos que para as (os) docentes trabalharem com os temas transversais é preciso capacitação e envolvimento de todas e todos da comunidade escolar e um conhecimento mais crítico-reflexivo acerca das sexualidades humanas.

A negação do currículo acerca do estudo do gênero e da sexualidade

Moreira e Silva (1997), afirmam que não há uma definição para currículo, pois o mesmo está relacionado a determinadas construções histórico-sócio-culturais. Segundo os autores supracitados, o currículo é carregado de ideologias, culturas e relações de poder de um grupo que está socialmente em posição de vantagem/superioridade em relação a outrem. Neste caso, estamos falando da cultura do adulto, masculino, branco, heterossexual, burguês, física e mentalmente "normal”. Silva (1996) afirma que:

O currículo é um dos locais privilegiados onde se entrecruzam saber e poder, representação e domínio, discurso e regulação. É também no currículo que se condensam relações de poder que são cruciais para o processo de formação de subjetividades sociais. Em suma, currículo, poder e identidades sociais estão mutuamente implicados. O currículo corporifica relações sociais. (SILVA, 1996, p. 23)

Neste trabalho, vamos considerar currículo como as ações praticadas nas escolas e nas universidades - cursos de formação de professoras e professores -, bem como o uso dos materiais - livros didáticos, vestimentas, arquitetura do ambiente escolar, etc - para o desenvolvimento do ser, pois entendemos que essas culturas, quando perpassadas, ensinam e regulam o corpo produzindo subjetividades e arquitetam formas e configurações de viver na nossa sociedade. Logo, a escola é um espaço onde essas 
culturas são transmitidas, hierarquizando e dando mais visibilidade ao modo heteronormativo de ser. Aos que fogem a essa regra, no caso aqui as (os) LGBT, terão que passar por anos de escolarização nos quais serão excluídos, reprimidos e silenciados o tempo todo.

Utilizando a letra da música de Chico Buarque, O que será?, Louro (2000) chama atenção para algo que "está na natureza” para todas e todos nós, a sexualidade, mas que historicamente tentaram/tentam negar, silenciar isso de nós, tanto o governo, a religião, assim como também os currículos educacionais. Porém, assim como na letra da música, Louro afirma que por mais negação e silenciamento, a sexualidade e as questões de gênero estão sempre no "centro dos discursos; estão a deixar o silêncio e o segredo e, por bem ou por mal, estão a provocar ruído, a fazer barulho e a fazer falar" (LOURO, 2000, p. 38). Porém, a mesma ainda nos alerta para o fato de que a natureza também é uma construção sócio- histórica e que, por isso, as identidades sexuais e de gênero não devem ficar presas às questões biologizantes.

Mulheres e homens produzem-se de distintas formas, num processo carregado de possibilidades e também instabilidades... Deste modo, pode haver e há muitas formas de ser feminina ou de ser masculino, e reduzi-las todas a um conjunto de características biológicas resulta, seguramente, numa simplificação... As formas de viver nossos prazeres e desejos não estão dadas, prontas, pela Natureza; há toda uma complexa combinação de sentidos, de representações, de atribuições que efetivamente vão constituir aquilo a que chamamos sexualidade. (LOURO, 2000, p. 39)

O currículo educacional nega/silencia as múltiplas formas de ser homem e mulher, assim como as diversas sexualidades que estamos estudando. Nos livros didáticos, nas atividades, nos discursos das (os) profissionais da educação estão presentes apenas representações e subjetividades promulgadas pelo homem, de classe média, branco, heterossexual, católico. As (os) docentes, mesmo lidando com turmas heterogêneas, desenvolvem seus trabalhos e avaliações de maneira única para todas e todos, 
esquecendo que ali estão diversas realidades - diferenças de raça, religião, classe social, orientação sexual, organização familiar, pessoas com deficiência, etc.

A escola, assim como a família e a religião, está apenas a formar homens e mulheres heterossexuais. Aqueles que fogem a esse padrão são marginalizados/silenciados, tendo que se adaptar às regras definidas por outrem. Os que não se adaptam são taxados com apelidos pejorativos, violentados física e verbalmente e acabam por viver no isolamento, alguns chegam até a se suicidarem por medo/vergonha de ser quem são.

O medo de ser descoberto/a, as gozações permitidas, a censura insinuada ou explícita levam a um verdadeiro apartheid sexual... Promove-se a segregação desses meninos/meninas e jovens... os quais vêem no isolamento uma forma de sobreviver. (LOURO, 2000, p. 52)

Cabe salientar que não haverá um currículo educacional que garanta aprendizagens de todas (os) alunas (os) se este não se preocupar de fato em incluir a diversidade das sexualidades e de gênero existentes em sala de aula. Para isso, precisa-se rever toda a formação docente, assim como também a organização do espaço escolar e transformar as instituições em locais que efetivamente possam fazer a diferença na vida dessas (es) alunas (os). Temos que lembrar, os currículos "não são meros transmissores de representações sociais que estão a circular nalgum lugar, são instâncias que carregam e produzem representações" (LOURO, 2000, p.56).

É necessário, assim, como afirma Fernando Seffner (2009), construir um ambiente de respeito e aceitação de mulheres, lésbicas, gays, bissexuais, travestis, transexuais e tantas outras sexualidades existentes e, para tal, exigem-se transformações na estrutura escolar, começando com

a abolição das piadas e das manifestações sexistas, tão comuns entre professores e professoras, acerca dos alunos e das alunas "diferentes" dos padrões heterossexuais ditos "normais". Não é possível educar num ambiente de falta de respeito, e a agressão - verbal e até mesmo física - 
tem sido uma arma de expulsão de indivíduos que não se enquadram na regra da heteronormatividade. (SEFFNER, 2009, p. 132)

Gênero e diversidade sexual na formação de professoras e professores

Primeiramente, não se tem como falar de formação de professoras (es), se não lembrarmos de fatos históricos que tornaram a docência uma profissão feminina. Pois se estabeleceu que as práticas das professoras deveriam ser semelhantes as do lar, tais como: cuidado, vigilância, afeto, confiança, papéis esses que foram designados para as mulheres. Disso também temos a questão da redução salarial para mulheres. Logo, caímos numa pergunta que é cercada de reflexões: se nas instituições educacionais as profissionais (em sua maioria) são mulheres como pode ser uma educação altamente machista e sexista?

Louro (2000) afirma que a escola é atravessada pelas relações de gêneros, uma vez que nela estão presentes mulheres, mas o conhecimento foi historicamente produzido por homens ${ }^{5}$. Porém, para efeito de estudos, vamos pensar aqui sobre mulheres e homens profissionais docentes, "refletindo sobre a educação escolar como um processo generificado, ou seja, como uma prática social que é constitutiva dos gêneros" (LOURO, 2000, p. 25).

Sabemos que nos cursos de formação de professoras e professores muitos temas importantes não são estudados ${ }^{6}$, mas não deixam de ser de suma importância para a formação docente. Como exemplo de um dos temas, incluímos os assuntos relacionados ao Gênero e Sexualidade que são trabalhados durante a graduação de Pedagogia na Universidade Federal de Pernambuco, porém de maneira que não abarcam todas (os) as (os) estudantes do Centro de Educação, pois as disciplinas de "Sexualidade e Educação" e de "Família, Gênero e Educação", que tratam desses temas, são eletivas, oferecidas apenas em um turno (diurno) e de pouca duração (um semestre, equivalente a 60 horas $)^{7}$. Algumas outras universidades têm ofertado cursos de formação continuada para

\footnotetext{
${ }^{5}$ Para maiores informações ver: LOURO, 2000.

${ }^{6}$ As disciplinas existem, porém essas informações não são transmitidas de forma clara aos discentes.

7 Esses dados foram tirados do perfil curricular do curso de Pedagogia da Universidade Federal de
} 
docentes, porém o que percebemos é que a maioria desses cursos é a distância. Ou seja, a formação de professoras (es) em relação à prática pedagógica que busque educar nossas (os) alunas (os) baseada nos princípios dos direitos humanos, respeitando a diversidade de gênero e a sexualidade do outro, ainda é incipiente nas nossas escolas e universidades.

Nos últimos anos houve um aumento das produções acadêmicas que discutem sobre gênero e diversidade sexual, porém o que observamos é que isso não é decorrente das práticas docentes e sim de esforços dos próprios estudantes, pois estes percebem a emergência de se trabalhar o tema em sala de aula, devido às constantes expressões da sexualidade infantil, assim como dúvidas e curiosidades das (os) jovens.

\section{Percurso metodológico da pesquisa}

\section{Abordagem Metodológica e Técnica de Coleta de Dados}

Por termos como objetivos investigar/compreender as concepções das (os) docentes sobre gênero e diversidade sexual na formação de professoras (es), nosso enfoque metodológico é uma abordagem qualitativa de pesquisa. Como instrumento metodológico, utilizamos a entrevista narrativa, uma vez que entendemos que esse recurso seja o mais adequado para a compreensão da memória, não só para tornar público o que pensam e sentem as (os) docentes, mas também uma forma de difundir o conhecimento produzido no seu dia a dia educativo (CUNHA, 2010).

O uso de narrativas das (os) docentes como estratégia de investigação para nossa pesquisa deve-se ao fato de que

procura sistematizar as experiências vividas pelos professores no contexto educacional e, através das informações concedidas por estes sujeitos, relacionar aos conhecimentos sobre o que os professores sabem, como produzem seus saberes, como transmitem o saber produzido. Essas buscas, identificam os conhecimentos utilizados no

Pernambuco. 
desenvolvimento de suas práticas pedagógicas, e a forma como constroem esses conhecimentos. Esse tipo de pesquisa oportuniza ao pesquisador compreender o processo de formação do sujeito, como também favorece a colocação do sujeito em lugar de destaque tornandoo um ator principal e autônomo nas questões relacionadas às suas aprendizagens. (CUNHA, 2010, p. 2)

Segundo Bauer e Gaskell, a entrevista narrativa vai muito além do esquema “pergunta-resposta”. Considerada um procedimento do tipo qualitativo, ela é entendida como uma entrevista não estruturada, com tipos específicos de comunicação linguagem espontânea -, o contar e escutar histórias para se alcançar os objetivos desejados na pesquisa. Porém, não significa dizer que a entrevista narrativa não esteja formalmente estruturada, pois ela segue um esquema, como dissemos acima, no qual o informante, no caso aqui a (o) docente, usa sua própria linguagem (BAUER e GASKELL, 2002).

Portanto, entendemos que a entrevista narrativa foi um excelente recurso metodológico, que permitiu a ressignificação da profissão docente, uma vez que as (os) professoras (es) reviveram suas trajetórias, suas experiências, seus valores, suas concepções e os saberes que permeiam suas práticas, permitindo que as lembranças fossem reorganizadas à medida que fatos passados eram trazidos para o presente, a fim de serem reinterpretadas, favorecendo o processo formativo realizado a partir da reflexividade sobre a prática pedagógica. Visto tudo isso, percebemos que a entrevista narrativa contribuiu bastante para nossa investigação, pois nos oportunizou trabalhar com a dimensão subjetiva das professoras e professores, instigando-os a exporem suas histórias de vida, o que favoreceu a expressão de suas angústias, situações conflituosas, construção de suas aprendizagens sobre os conteúdos de gênero e diversidade sexual, concepções que guiam sua prática pedagógica e características de sua prática docente com relação às temáticas dessa pesquisa. (CUNHA, 2010).

As professoras (es) entrevistadas (os) se identificaram como bissexuais e heterossexuais, vinculadas (os) às redes municipal e estadual da cidade do Recife. Inicialmente, pretendíamos entrevistar também professoras (es) lésbicas, gays, travestis 
e transexuais, mas as (os) sujeitas (os) que foram localizadas (os), que tinham essas identidades sexual e de gênero não eram da rede municipal de ensino, nem estadual, sendo residentes em outros estados ou não mais trabalhando como docentes. Para encontrarmos as (os) docentes para a realização da entrevista, fomo na GLOS (Gerência de Livre Orientação Sexual) vinculada à Secretaria de Desenvolvimento Social e Direitos Humanos da Prefeitura do Recife, onde conseguimos uma lista com os nomes das (os) professoras (es) da rede.

\section{Procedimento de Coleta de Dados}

Para realizarmos a coleta dos dados, inicialmente, apresentamos às (aos) entrevistadas (os) os objetivos do trabalho, assim como também uma ficha de identificação e um termo de consentimento, no qual garantimos o sigilo da identidade de todas e todos. As entrevistas foram registradas em gravadores e duraram em média 30 minutos cada.

\section{Caracterização dos sujeitos e do campo}

Entrevistamos quatro docentes, que se identificaram como: duas heterossexuais e dois bissexuais. Para fins de análise, suas identidades serão mantidas no mais absoluto sigilo, portanto, os nomes que iremos citar são fictícios, escolhidos por mim e/ou por elas (es) mesmos. As heterossexuais, chamaremos de Rose e Merida ${ }^{8}$; os bissexuais, chamaremos de Rudolf ${ }^{9}$ e Erton $^{10}$.

\footnotetext{
${ }^{8}$ Merida, personagem do filme infantil "Valente", é uma princesa que não quer seguir a tradição da nobreza: não pretende se casar e quer viver livre, cavalgando pelas montanhas da Escócia em busca de aventuras. Pela maneira com essa professora narrou sua história de vida, suas concepções sobre gênero e diversidade sexual, percebi muitas semelhanças com a personagem, por isso escolhi esse codinome.

9 Nome de um dos mais celebrados bailarinos do século 20, Rudolf Nureyev foi o primeiro homem superstar do mundo da dança. Escolhi esse nome pelo fato do professor ter citado a todo o momento que é do meio artístico/dançarino.

${ }^{10}$ Nome escolhido pelo próprio entrevistando, uma vez que Erton foi um grande companheiro seu. Erton, ator e estudante do curso de Pedagogia da Universidade Federal de Pernambuco (UFPE-Campus de Caruaru), que foi assassinado, com aproximadamente 15 facadas, justamente por ser homossexual e não
} 
As (os) entrevistadas (os) têm entre 27 e 50 anos, com formação em Pedagogia, Letras e Biologia. Algumas (os) são militantes das causas LGBT, outro trabalha também como artista/dançarino. Tempo de trabalho delas (es) varia entre 2 e 24 anos de atuação na rede pública de ensino. Suas rendas mensais variam entre 1 e 6 salários mínimos.

\section{Procedimento de Análise dos Dados}

Primeiramente, para fins da análise, realizamos a transcrição integral de todas as entrevistas. No segundo momento, fizemos a exploração dos dados a partir de leitura em profundidade dos mesmos, organizando-os, em seguida, por agrupamento de respostas significativas, formando eixos temáticos orientados por nossos objetivos específicos. No terceiro momento, a partir das palavras significativas encontradas, fizemos as inferências em relação às mesmas fundamentando as interpretações segundo o aporte teórico estudado.

\section{Resultados e discussão}

Concepções dos docentes sobre gênero e diversidade sexual

O estudo sobre gênero e diversidade sexual ainda é muito escasso no campo da educação. O estudo de gênero e da sexualidade não é abordado nas escolas e quando esses conteúdos são trabalhados, predominam perspectivas biologizantes e moralizantes-preventivas com foco na gravidez na adolescência e doenças sexualmente transmissíveis DST/Aids, sendo ministrado comumente por docentes da área de ciências/biologia. Para mudar essa realidade foram criados os PCN's, para que esses conteúdos fossem trabalhados como temas transversais (FAVA, 2008). Como nossas (os) docentes não estão preparadas (os) para isso, acabam reproduzindo concepções sexistas e heteronormativas, adquiridas na maioria das vezes, na mídia, na família e no meio religioso. Abaixo, seguem depoimentos de docentes que não se contentaram com as 
concepções apreendidas durante sua educação escolar; estes, como afirma Fava (2008) ao destacar algumas propostas de inclusão da Educação Sexual, se deram conta de seu despreparo com relação ao tema transversal e foram em busca de novos conhecimentos, através de leituras, inserção em movimentos sociais (feministas e LGBT), em diálogos com amigas (os).

O que eu tenho como base do espaço escolar, da construção da minha trajetória na escola, na universidade, etc, é aquela concepção de que gênero está atrelado ao sexo e que esse gênero, ele tem que responder ao sexo, então se eu tenho pinto eu tenho que ser um homem, se tenho uma vagina eu tenho que ser mulher, então tipo, seu gênero, a sua identidade de gênero vai partir do que você tem no meio das pernas, seu órgão sexual, é uma anatomia sexual que vai definir sua identidade. (Professor Erton, 27 anos)

... eu me lembro que a primeira vez que eu fui entender o que era um gay eu tive um choque, eu tive nojo, eu não queria conversar com pessoas que tivessem trejeitos ou pessoas que davam sinal de ser gay... Eu nunca via a escola na minha época trazer isso como ponto de reflexão, havia muito estereótipo. (Professora Merida, 29 anos)

... durante o ensino fundamental e médio essas questões [gênero e diversidade sexual] quase não eram trabalhadas em sala de aula... (Professor Rudolf, 30 anos)

Vale ressaltar que algumas (os) das (os) entrevistadas (os) não têm mais essas concepções arraigadas em seu dia a dia atualmente, devido à curiosidade em buscar novos conhecimentos, à inserção na militância LGBT e à convivência com amigas e amigos do mesmo meio. Portanto, as concepções citadas acima foram as apreendidas antes de suas experiências em contextos de educação formal e não formal.

Ficou perceptível como a religião, a mídia e as instituições escolares, com seus diferentes recursos, contribuem de modo significativo na construção do mundo, produzindo subjetividades e identidades, discursos e práticas de poder, trabalhando a separação dos gêneros, a regulação dos corpos e a reprodução de preconceitos e 
discriminações a determinados grupos que não correspondem à norma padrão estabelecida pela sociedade.

Ah... alguns [alunos] a gente percebe as preferências de comportamento sexual desde pequeno, ou que vão se decidindo ou aflorando ao longo da vida. Pra mim em sala de aula todos são iguais, tanto em sala, quanto perante ao criador, são todos iguais. (Professora Rose, 50 anos)

No extrato acima, percebemos que a professora se utilizou da religião para justificar uma suposta aceitação da diferença, porém sabemos da intolerância que a religião tem com as (os) LGBT, principalmente a católica e a evangélica, quando afirmam que a Igreja tolera o pecador, mas não o pecado, ou seja, ama todas (os) LGBT, mas não tolera o ato sexual praticado por elas (es), exemplo fiel de uma falsa aceitação das diferenças.

\begin{abstract}
Vinha dessa educação que tava me preparando para ser uma princesa, eu tinha que ficar esperando o homem vir e me conquistar, era isso, eu não podia sair pra procurar, eu não podia ter esse movimento de eu escolher e assumir meu desejo, eu tinha que ficar no meu lugar, esperando que alguém viesse e me colocasse em cima do cavalo branco e fosse embora né? Era assim. (Professora Merida, 29 anos)
\end{abstract}

No depoimento acima, percebemos de forma bastante compreensível a atuação da mídia e dos contos de fada que são perpassados todos os dias em filmes, telenovelas, livros, etc; desde a educação infantil, essas são as representações de gênero e sexualidade que sustentam as práticas cotidianas de todas (os) nós, ensinando-nos a sermos mulheres e homens desde pequenos e a família que devemos formar. A mulher aparece sempre no papel subalternizado, pronta pra casar, cuidar da casa e ter filhas (os), sufocando qualquer outra sexualidade que possa desejar, pois a sua descoberta pode acarretar sua exclusão, e incomodar aqueles que estão a sua volta. Michele Escoura Bueno, em seu estudo sobre imagens de princesas de contos de fadas, afirma que em 
seus estudos o ser mulher está associado ao casamento e filhas (os). Segundo a mesma autora, a felicidade só é alcançada quando a princesa se casa, e ela quase sempre não faz nada para chegar a esse resultado. É sempre passiva, à espera de sua vida mudar (BUENO, 2013).

Segundo Louro, é a voz socialmente aprovada/autorizada que inclui e exclui sujeitos e conhecimentos, deliberando apenas quais as identidades ou os saberes que podem integrar o currículo. Abaixo segue o extrato do professor Erton, no qual ele afirma que o currículo é excludente, uma vez que segue o modelo heteronormativo, isso porque alguém se achando superior a outrem firmou essa como uma "maneira correta de se viver". No depoimento abaixo está exposto como a escola, com esse seu currículo heteronormativo exerce sua função disciplinando os corpos, muitas vezes de maneira sutil, discreta e contínua, mas altamente eficiente para os moldes que ele quer criar (LOURO, 2000).

(...) pra quem fez, ele [currículo] tá perfeito! Porque ele tá conseguindo atingir seus objetivos que é formar esses corpos, é reproduzir a heterossexualidade, os padrões e aumentar o preconceito; se você fugir ao padrão, a sociedade tá aí pra lhe discriminar e lhe sujeitar aos mais variados tipo de violência. (Professor Erton, 27 anos)

Experiências de vida que colaboraram de modo significativo para suas concepções sobre gênero e diversidade sexual

Por conta de todo esse preconceito enraizado pelo sistema educacional, religioso, midiático, nossas (os) entrevistadas (os) buscaram outro meio para adquirirem novas concepções não hegemônicas. Mas isso não se deu automaticamente, muitos deles praticaram atos de violência lesbofóbicas, homofóbicas, bifóbicas e transfóbicas antes dessa ressignificação de valores, como também passaram por violências que marcaram de modo significativo suas vidas deixando marcas em suas subjetividades. Vejamos a seguir algumas lembranças de violências sofridas e/ou praticadas por nossas (os) entrevistadas (os). 
Já tive alunas transexuais e que inclusive fazia: eu não gosto do meu nome, eu quero ser chamada pelo meu nome atual, mas o meu comportamento na sala de aula é pra mim você é aluno, em sala de aula respeito sua preferência sexual, mas chamada, e tratar, eu tenho que tratar com o que ele está registrado. (Professora Rose, 50 anos)

O depoimento que vamos ler agora foi da professora Merida, antes desta criar as concepções que ela tem hoje, afirmando ter sido através da leitura e de amigas (os) que ela desconstruiu suas concepções anteriores. Segundo ela, esse episódio marcou decisivamente em sua busca por mais conhecimento sobre as causas LGBT.

(...) foi exatamente no momento que eu comecei a criar grupos de amigos... e aí nesse grupo tinha três homossexuais, um era assumido e dois não. Um deles, eu me apaixonei, tentei convertê-lo o máximo possível (risos) não consegui e um não falava das questões, não tinha trejeitos, então eu achava que ele não era homossexual (...) e aí esse menino que não era assumido declarou um dia que tinha muito medo que eu descobrisse, porque em algumas falas que eu tinha era de não aceitação e eu fiquei muito triste quando ele disse isso (lágrimas - tanto da entrevistada, quanto minha). Eu fiquei muito triste porque eu disse: 0 que eu tô fazendo? (silêncio e mais lágrimas de ambas ${ }^{11}$ ) $\mathrm{E}$ aí eu me coloquei no lugar dele... (Professora Merida, 29 anos)

Sabemos que atitudes lesbofóbicas, homofóbicas, bifóbicas, transfóbicas marcam distâncias, estigmatizam e atribuem modos de ser e agir, ao mesmo tempo em que sancionam atos que variam do desdém à violência. Isso foi o que aconteceu com algumas (uns) de nossas (os) entrevistadas (os) durante sua escolarização. Seguimos com o depoimento da professora Merida, que afirma muitas vezes, ainda hoje, ter sua sexualidade questionada, pois a todo o momento perguntam se ela é "sapatão":

\footnotetext{
${ }^{11}$ Entrevistadora e entrevistada.
} 
Por que você não usa salto alto? Por que você não usa batom vermelho? Ou por que você não usa uma blusinha mais decotadinha? E eu ficava muito triste... Então quando o homem vira pra você e faz assim: por que você não tá usando isso que legitima sua feminilidade? Eu me sentia afetada... Então eu precisei buscar apoio psicológico pra poder entender isso, e aí eu comecei a investigar meu passado (olhos cheios de lágrimas), e foi que eu comecei a encontrar algumas respostas do porque isso acontecia... (Professora Merida, 29 anos)

O corpo é regulado, marcado cotidianamente, como disse uma/um de nossas (os) entrevistadas (os); as pessoas passam a ser "policiais reguladores dos corpos dos outros". Segundo Meurer (2009), a todo o momento são veiculados na televisão, em jornais e revistas estereótipos, modos de se vestir e corpos perfeitos, que acabam por impor esses modelos à sociedade, gerando sofrimento psíquico e uma total inadequação com a própria imagem por parte daquelas que não se enquadram nos padrões de belezas estabelecidos pela mídia (MEURER, 2009). Reforçando essa ideia, Pegoraro (2010), utilizando Louro como referencial, afirma que as instituições escolares, que deveriam quebrar com esses valores, acabam por reforçar apenas um modo "adequado e normal" de ser homem e mulher, concebendo a heterossexualidade como natural e universal (PEGORARO, 2010 apud. Louro, 2005). Devido a esses fatores, as (Os) alunas (os) que fogem a essa regra passam por violências que são das mais variadas possíveis, simbólicas, verbais e até mesmo físicas.

Eu lembro de mim, que eu tava na escola na $8^{\circ}$ série e eu sempre gostei de carregar o caderno assim ( $\mathrm{fez}$ indicação com os braços apontando um modo de segurar os cadernos como uma mulher, segundo os padrões heteronormativos), e sempre era chacoalhado por carregar o caderno assim, porque quem carrega o caderno no peito é menina, menino carrega o caderno assim (indicou o padrão masculino de carregar o caderno)... as pessoas vinham regular meu corpo, todas as crianças, isso não é jeito, e eu ao continuar, claro que não me sentia bem, claro que isso me fazia mal né? Muito mal! Por dentro eu tava uma merda! O fato de eu continuar gerava muito mais violência, gerava muito mais agressão física, agressão verbal e apelidos e tal. (Professor Erton, 27 anos)

(...) eu lembro que eu levei cuspida até no meu rosto em sala de aula porque é, eu sempre fui muito molinho (...) eu sempre ficava mais próximo das meninas do que dos meninos, então assim, minhas 
brincadeiras eram mais voltadas pra ficar com as meninas, então assim, foi uma coisa que foi forte pra mim, sabe? Porque você ser cuspido no rosto por nada, simplesmente porque você é... não fazer parte de determinado grupo, né? Então isso foi algo que me marcou muito... (Professor Rudolf, 30 anos)

Através dos depoimentos acima, percebemos como a escola atua na educação dos corpos das nossas alunas (os), sem respeitar a diversidade de jovens que nela estão inseridos. A diversidade dos corpos está cada vez mais ausente do currículo escolar, "ignora-se o corpo negro, o corpo homossexual, o corpo tatuado, não se discute os tantos outros corpos que estão na escola" (PEGORARO, 2010, p. 38).

Aspectos de sua formação docente que circunscrevem suas concepções

De acordo com as entrevistas realizadas, percebemos que as concepções das (os) docentes acerca de gênero e diversidade sexual que as (os) entrevistadas (os) têm hoje, não foram apreendidas nas instituições escolares, nem mesmo nas academias. De acordo com os relatos, observamos que essas concepções foram adquiridas ao longo da vida pessoal, na convivência com amigas (os) de orientação sexual LGBT e na curiosidade de buscar mais conhecimento de si. Isso se deve ao fato de que foram nesses espaços, nessa rede de amigas (os) que as (os) entrevistadas (os) encontraram uma maior aceitação, amor e cuidado. Segundo a pesquisa realizada por Sasha Roseneil ${ }^{12}$ a amizade é mais especial para lésbicas e homossexuais, uma vez que as (os) mesmas (os) são rejeitadas (os) pelos familiares, encontrando nos amigos equilíbrio emocional, companhia, prazer e ajuda no plano prático (ROSEINEIL, 2006). Acrescentamos aqui que amizade é também do mesmo modo para bissexuais, travesti e transexuais que não foram citadas na pesquisa de Roseneil.

\footnotetext{
${ }^{12}$ Pesquisa intitulada "Viver e amar para lá da heteronorma: Uma análise queer das relações pessoais no século XXI".
} 
(...) então eu acredito na influência de amigos (...) em diversos setores, tanto acadêmico, quanto artístico, porque eu trabalho com dança, aí os valores são diferentes, as concepções são diferentes (...) eu acho que esse fator mais fraterno é que eu trago como algo bastante significativo. (Professor Rudolf, 30 anos)

É, existem duas coisas, filosofia de vida pra mim, duas coisas que me fazem abrir a cabeça, conviver com gente e ler, quando eu tava perto de sair de casa é, eu sabia que muitos dos valores que eu tinha ia ficar pra trás, e aí foi exatamente, como nada acontece por acaso, foi exatamente no momento que eu comecei a criar grupos de amigos, eu comecei a andar em grupo com pessoas, né? (Professora Merida, 29 anos)

(...) foi a partir dessa percepção de ver que tavam construindo em mim algo, que tavam me impondo algo que eu passei a questionar esse algo e construí outro algo, que é esse outro algo que eu sou hoje, que eu acredito que a possibilidade da não heterossexualidade, a possibilidade das diversas identidades de gênero ou da não identificação de gênero, que a pessoa se trate como ser humano e pronto. (Professor Erton, 27 anos)

Também temos depoimentos de professoras (es) que são aqueles construídos desde a educação infantil, aquela concepção biologizantes.

Eu trabalho com alunos dos dois gêneros, masculino e feminino... a gente só tem dois sexos; cientificamente é determinado que produz óvulo pertence ao sexo feminino, produz espermatozoide masculino. Agora a questão de a preferência sexual ela vai se desenvolver junto com a personalidade de cada um, personalidade, caráter... (Professora Rose, 50 anos)

\section{Repercussões dessas concepções no contexto escolar}

As questões de gênero e diversidade sexual são tratadas apenas de maneira específica nas disciplinas de ciências e biologia, em que estudamos sobre gravidez precoce, doenças sexualmente transmissíveis DSTs/Aids e reprodução humana, porém este conteúdo aborda questões da anatomia e fisiologia humana, deixando de lado outras questões referentes a sexualidade humana. Isso fica claro no depoimento abaixo: 
(...) vou trabalhar questões de doenças sexualmente transmissíveis; o que a gente vai enfocar são causa, consequências e cuidados... então, vamos trabalhar somente formas de contagio e prevenção, não é? Sintomas, claro, mas só os sintomas. (Professora Rose, 50 anos)

Algumas (uns) professoras (os) que já têm algum conhecimento da causa tentam fazer um paralelo com as disciplinas abordadas, outras (os) tratam apenas do assunto quando os mesmos são abordados em sala de aula pelas (os) estudantes.

(...) pela minha vivência artística eu procuro trabalhar essa questão da diversidade no cunho mais amplo que é o cunho da corporeidade, tá entendendo? Porque a corporeidade ela se expressa de diversas maneiras, então assim, a corporeidade ela desperta a questão de desejos, de anseios, de satisfações, é o seu corpo, é como você se sente, enfim, então eu procuro fazer esse link, né? (Professor Rudolf, 30 anos)

(...) na minha prática, eu procuro não reproduzir, sem discursos heteronormativos e tal, de no dia a dia tentar mostrar outras formas possíveis de se viver, quando falo de família, falo de todo tipo de família (...) então é o fato de não se calar, é o fato de problematizar isso, claro que você não vai em pouco tempo, nem talvez nem muito tempo até porque essas opiniões são construídas nos mais variados espaços e a escola é só um deles, os espaços de educação é só um deles, formais e não formais, você não vai conseguir desconstruir isso totalmente, até porque enquanto você desconstrói, a televisão tá construindo, a igreja tá construindo, então você vai ficar nessa luta que é totalmente desleal, mas o mínimo que você pode fazer enquanto educador é problematizar isso, tirar isso do obscuro, do xingamento e problematizar tudo que acontecer com relação a isso. (Professor Erton, 27 anos)

Como o currículo contribui para o estudo de gênero e diversidade sexual

Sabemos que as (os) estudantes passam por um processo de ensino e de aprendizagem que colabora expressivamente na/para a sua formação enquanto cidadã (o) crítica (o), ativa (o) e reflexiva (o) em relação aos valores éticos, morais e sociais, que são constantemente difundidos em diversos discursos institucionais em nossa sociedade. Compete às instituições educacionais o papel de gerar estratégias de ensino que 
possibilitassem uma formação voltada para os direitos humanos, que levasse a (o) educanda (o) a respeitar a diversidade do outro, seja ela étnica, racial, orientação sexual ou de gênero.

Mas infelizmente, o que é presenciado ao longo dos anos é uma ausência nos currículos educacionais referente ao estudo de gênero e diversidade sexual, como se nossas (os) alunas (os) fossem todas (os) heterossexuais e se adaptassem perfeitamente às práticas discursivas impostas por uma sociedade sexista e heteronormativa. Ao longo da história, as instituições educacionais se preocuparam apenas em disciplinar e regular os corpos. Mas, segundo Louro, as instituições ao mesmo tempo em que tentaram negar/silenciar as questões de gênero e sexualidade, dela mais se ocupou, uma vez que é nessas instituições que são formadas as identidades de gênero e sexualidade das (os) sujeitas (os), “com padrões claramente estabelecidos, regulamentados e legislação capazes de separar, ordenar e normalizar cada um/uma e todos/as" (LOURO, 2000, p. 47).

Mas discussões sobre o tema ainda são negadas pelo currículo, logo, as (os) alunas (os) ditas (os) diferentes, como as lésbicas, bissexuais, gays, travestis e transexuais, são a todo o momento vítimas do preconceito. Outro argumento bem comum é que se tais assuntos não forem falados em sala de aula, mais distantes e protegidas (os) as (os) alunas (os) ficarão. Abaixo vemos os depoimentos das (os) professoras (es) acerca do estudo de gênero e sexualidade durante suas escolarizações:

Eu nunca via a escola na minha época trazer isso [estudo de gênero e diversidade sexual] como ponto de reflexão, havia muito estereótipo, havia muito, assim, práticas que reforçavam a separação das pessoas, as pessoas é, ditas diferentes não é? (Professora Merida, 29 anos)

Dentro da própria academia eu acho que só vivenciei algo sobre em psicologia, em duas cadeiras de psicologia. (Professor Rudolf, 30 anos)

Mesmo havendo um maior número de pesquisas sobre o assunto nos últimos anos, o que observamos é que o mesmo ainda é visto como um tabu para a sociedade e para as instituições educacionais; logo, o que percebemos são professoras (es) 
totalmente despreparadas (os) para lidar com essas questões em sala de aula, reproduzindo discursos e atitudes discriminatórias e/ou se omitindo diante de cenas de violências para com alunas (os) que não seguem os padrões estabelecidos por nossa sociedade.

(...) eu acho que o profissional por não ter essa formação sabe? Não vivenciou isso e quando vivencia ainda é cheio de pudores... eu acredito que muitas vezes o profissional não trabalha de forma mais pontual, mais concisa dentro da sala de aula por ele não ter essa formação e não se achar apto para realizar e discutir com seus alunos essa questão porque é um tabu. (Professor Rudolf, 30 anos)

Eu acho que a formação atinge o que ela quer, ela tem êxito porque ela quer formar esses corpos, corpos heterossexuais nos padrões e quer que o professor faça isso, o professor diz que é uma má formação, diz que não foi formado pra isso, não, ele não foi formado pra educar corpos livres, ele foi formado pra educar corpos adequados, disciplinado e bem ajustado naquele padrão e a recriminar os corpos não ajustados. (Professor Erton, 27 anos)

De acordo com as entrevistas que realizamos, percebemos que nossas (os) entrevistadas (os) sofreram e/ou praticaram muitas cenas de violência e exclusão no sistema educacional da cidade do Recife em se tratando das questões de gênero e diversidade sexual. Isso se deve ao fato da existência de um currículo que tenta nos regular, formatando corpos disciplinados, dos PCN's que ficam nas prateleiras da biblioteca, das (os) professoras (es) que se omitem diante das ofensas e violências cometidas pelos "policiais reguladores dos corpos dos outros". Os conhecimentos das (os) professoras (es) entrevistadas (os) não foram adquiridos em sua educação formal, nem básica, nem acadêmica, mas sim nos movimentos sociais em que estão inseridas (os), pois três delas (es) são militantes das causas feministas e LGBT. 


\section{Considerações finais}

Este trabalho contribuirá como fonte de pesquisa para docentes em formação e já formados, dos cursos de Pedagogia e Licenciaturas diversas para que estes possam refletir sobre formação de professoras e professores a respeito das relações de gênero e diversidade sexual, assim como para qualquer pessoa interessada no assunto.

Sabemos como as questões das sexualidades humanas são consideradas tabus para a sociedade, seja no campo familiar, religioso, midiático ou educacional A diversidade sexual e as relações de gênero não são esmiuçadas em seus múltiplos aspectos, eternizando práticas excludentes e discriminatórias que naturalizam uma determinada forma de exercício dos desejos e criminalizam qualquer outra forma de manifestação, através da utilização de diversos mecanismos de violência - verbal, física, emocional.

Este artigo tem como base a quebra do silêncio e a problematização de assuntos ligados à questão de gênero e diversidade sexual. A inserção desta discussão foi essencial para o reconhecimento das diversas identidades no espaço escolar e acadêmico, assim como levantou a consciência sobre a necessidade da realização de uma prática profissional docente que contribua para a veiculação dos ideais dos direitos humanos em interface com os direitos sexuais, garantindo o acesso de todas e todos à educação através do respeito à diversidade.

Ao longo das entrevistas que realizamos, pudemos perceber como a educação dessas pessoas foi cercada de tabus e silêncio em relação às questões de gênero e diversidade sexual, uma vez que nos depoimentos delas (es) estão presentes cenas de violências, tanto praticadas, como sofridas. Percebemos também como a mídia e a religião (mais marcante a cristã) são importantes ferramentas, formadoras de ideologias com seus discursos e práticas de poder, trabalhando a regulação dos corpos, o modelo de família que devemos formar, reproduzindo preconceitos e discriminações a determinados grupos que não correspondem à norma padrão estabelecida por esses veículos de informação. 
Ao longo de sua formação, três, das (os) quatro entrevistadas (os), ressignificaram

suas concepções, isso através da sua inserção nos movimentos sociais (feministas e LGBT), na construção de redes de amigas (os), na busca de novos conhecimentos em leituras diversas. Tais atitudes levaram as (os) docentes entrevistadas (os) a manterem uma consciência coletiva diante dos temas em questão, passando então a rever seus conceitos sobre gênero e diversidade sexual. Além do mais, dois, das (os) quatro docentes entrevistadas (os) se declararam como bissexuais, o que nos levar a considerar que suas concepções foram advindas do seu próprio histórico de exclusão e opressão durante sua educação escolar, o que os tornou mais críticos/reflexivos diante da imposição de uma regra na qual eles não pertenciam/não seguiam.

Três das (os) quatro docentes afirmaram também que o currículo em nada contribuiu para suas formações docentes, mas isso também ficou claro durante as narrativas dessas pessoas ao longo de suas vivências escolares, pois muitas (os) delas (es) não se perceberam como "iguais" às (aos) outras (os) estudantes, justamente pelas práticas e discursos utilizados pela sociedade serem cheios de machismos, impregnados de preconceitos e práticas discriminatórias para aquelas (es) que não correspondem socialmente ao gênero compatível com seu sexo biológico. As instituições educacionais, no lugar de trabalhar essas questões em sala de aula, se omitem ou mesmo reproduzem essas atitudes, formando em grande parte das (os) alunas (os) ideologias sexistas e lesbofóbicas, homofóbicas, bifóbicas e transfóbicas. 


\section{Referências}

ALTMANN, Helena. Orientação sexual nos Parâmetros Curriculares Nacionais. Estudos

Feministas, 2001. IN: www.scielo.com.br

ANDRADE, Luma Nogueira. Travestis na escola: Assujeitamento ou resistência à ordem normativa. Tese de doutorado, 2012. Universidade Federal do Ceará, Programa de Pósgraduação em Educação Brasileira.

BAUER, Martin, W.; GASKELL, George (Editores) Pesquisa qualitativa com texto, imagem e som: um manual prático. Petrópolis, RJ: Vozes, 2002.

BUENO, Michelle Escoura. Contos de fada perpetuam preconceito. IN:

http://tribunadoplanalto.com.br/index.php?option=com_content\&view=article\&id=16211:C ontos-de-fada-perpetuam-preconceito $\&$ catid=60:escola \&ltemid=8

CUNHA, Lidenora de Araújo. A pesquisa narrativa no contexto da formação docente. IN: http://www.ufpi.br/subsiteFiles/ppged/arquivos/files/VI.encontro.2010/GT.1/GT_01_08.pdf

DAHMER, Tatiana. Gritos Silenciados, Mas Evidentes. Loyola, 2003.

FAVA, Carolina Andaló. Sexualidade como tema transversal nas escolas: da teoria à prática. Gênero e pesquisa em psicologia social, 2008.

LOURO, Guacira Lopes. Heteronormatividade e Homofobia. Diversidade sexual na educação: problematizações sobre a homofobia nas escolas. Brasília: MEC/Secretaria de Educação Continuada, Alfabetização e Diversidade, UNESCO, 2009.

. Gênero, sexualidade e educação: uma perspectiva pós-estruturalista. Petrópolis, Rio de Janeiro: Vozes, 2011.

. Currículo, Gênero e Sexualidade. Porto, Portugal: Porto Editora, 2000.

MEURER, Bruna. A fabricação cultural dos corpos femininos através da mídia. Salvador, BA, 2009. Seminário Internacional Enlaçando Sexualidades: Educação, Saúde, Movimentos Sociais, Direitos Sexuais e Direitos Reprodutivos.

MOREIRA, Antônio Flávio Barbosa; SILVA, Tomaz Tadeu. (Org.). Currículo, cultura e sociedade. 2. ed. São Paulo: Cortez, 1997. 
PEGORARO, Seris de Oliveira Matos. A ditadura do corpo perfeito: um estudo das representações sociais sobre corpo a partir de uma oficina pedagógica. Revista Didática Sistêmica, Volume 12, 2010.

REIDEL. Marina. A pedagogia do salto alto - Histórias de professoras transexuais e travestis na Educação Brasileira. Dissertação de Mestrado, 2013. Universidade Federal do Rio Grande do Sul.

ROSENEIL, Sasha. Viver e amar para lá da heteronorma: Uma análise queer das relações pessoais no século XXI. Revista Crítica de Ciências Sociais, 2006.

SEFFNER, Fernando. Equívocos e Armadilhas na Articulação entre diversidade Sexual e Políticas de Inclusão Escolar. Diversidade sexual na educação: problematizações sobre a homofobia nas escolas. Brasília: MEC/Secretaria de Educação Continuada, Alfabetização e Diversidade, UNESCO, 2009.

SILVA, Tomaz Tadeu da. Identidades terminais: as transformações na política da pedagogia e na pedagogia da política. Petrópolis: Vozes, 1996.

SIQUEIRA, Wiliam Peres. Cenas de Exclusões Anunciadas: travestis, transexuais, transgêneros e a escola brasileira. Diversidade sexual na educação: problematizações sobre a homofobia nas escolas. Brasília: MEC/Secretaria de Educação Continuada, Alfabetização e Diversidade, UNESCO, 2009.

http://www.doistercos.com.br/ggb-divulga-numero-de-assassinatos-de-gay-no-ano-de2012/

http://www.sul21.com.br/jornal/a-escola-ainda-e-um-espaco-homofobico-e-transfobico-diz-marinareidel/ 
Recebido em: 26/03/2014 Aprovado em: 26/08/2014

Universidade do Estado de Santa Catarina - UDESC

Centro de Ciências Humanas e da Educação - FAED

Revista PerCursos

Volume 15 - Número 02 - Ano 2014 revistapercursos@gmail.com 